\title{
OS ANIMAIS, A NATUREZA E AS TRÊS ECOFILOSOFIAS
}

\begin{abstract}
ANIMALS, THE NATURE AND THE THREE ECO PHILOSOPHIES
\end{abstract}
\author{
${ }^{1}$ Heron José de Santana Gordilho \\ ${ }^{2}$ Raissa Pimentel Silva
}

\section{RESUMO}

O presente artigo analisa o status moral e jurídico que as principais correntes da filosofia ambiental reivindicam aos animais e à natureza em geral. A partir de uma revisão bibliográfica, o escrito analisa inicialmente as duas principais correntes antropocêntricas, a saber: o antropocentrismo puro e o antropocentrismo alargado. Em seguida, dedica-se à análise das teorias animalistas, contemplando as correntes abolicionistas e bem-estarista.Por fim,analisa as premissas que fundamentam a Ecologia Profunda, ética ambiental que reivindica a inclusão dos animais e da natureza na esfera da moralidade.

Palavras-chave: Antropocentrismo, Antropocentrismo alargado, Ecologia profunda, Abolicionismo animal, Bem-estar animal

\begin{abstract}
This article analyzes the moral and legal status to the mainstream of environmental philosophy claim to animals and nature in general. From a literature review, the article initially analyzes the two main streams anthropocentrism, as pure anthropocentrism and the extended anthropocentrism. Then the article analyzes the animalistic theories, as wellfarist and abolitionists. Finally, it analyzes the assumptions underlying the Deep Ecology, environmental ethics which claims the inclusion of animals and nature in the circle of morality.
\end{abstract}

Keywords: Extended anthropocentrism, Deep ecology, Animal rights, Animal welfare

\footnotetext{
${ }^{1}$ Doutor em Direito pela Universidade Federal de Pernambuco, UFPE, Recife - PE (Brasil). Professor da Universidade Federal da Bahia - UFBA, Salvador - BA (Brasil) E-mail: heron@ufba.br

${ }^{2}$ Doutorando em Direito na Universidade Federal da Bahia, UFBA, Salvador - BA (Brasil). Professora da Universidade Federal da Bahia, UFBA, Salvador - BA (Brasil). E-mail: raissa.pimentel@ sema.ba.gov.br
} 


\section{INTRODUÇÃ̃O}

A Constituição Federal de 1988 estabelece, no caput do artigo 225, que todos têm direito ao meio ambiente ecologicamente equilibrado, bem de uso comum do povo e essencial à sadia qualidade de vida, impondo-se ao Poder Público e à coletividade o dever de defendêlo e preservá- lo para as presentes e futuras gerações. ${ }^{1}$

Nos termos do artigo 225, $\S 1^{\circ}$, inciso VII, a Carta Magna, ainda, proíbe expressamente todas as práticas que coloquem em risco a função ecológica associada à fauna e flora, provoquem a extinção de espécies ou os submetam à crueldade, ${ }^{2}$ ao passo que os artigos 29 e 32 da Lei Federal n 9.605, de 12 de fevereiro de 1998, que dispõe sobre as sanções penais e administrativas aplicáveis às condutas e atividades lesivas ao meio ambiente, tipificam como crime a morte, prisão e os maus-tratos de animais silvestres, domésticos ou domesticados. ${ }^{3}$

Sem embargos, em uma constituição principiológica como a brasileira, a interpretação de tais normas de direitos fundamentais exige um prévio embasamento filosófico, pois a depender da visão ecológica do intérprete, pode-se chegar a soluções jurídicas bem distintas.

De fato, com a efervescência dos movimentos ecológicos - especialmente a partir dos anos 1970 - o homem passou a perceber a necessidade de repensar a sua relação não somente com o meio em que o cerca, mas com os demais animais não humanos.

Neste horizonte, a heterogeneidade axiológica torna-se latente, emergindo daí sistemas éticos permeados por valores distintos, com alguns pontos de intersecção, mas em outros aspectos bem dissonantes.

Este artigo irá inicialmente analisar as características centrais da lógica antropocêntrica, consignando os fundamentos teóricos que possibilitaram a sua sedimentação como paradigma dominante, tanto em sua versão pura quanto alargada.

\footnotetext{
1 BRASIL. Constituição (1988). Constituição da República Federativa do Brasil. Brasília, DF: Senado Federal: Centro Gráfico, 1988. Artigo 225.

2 BRASIL. Constituição (1988). Constituição da República Federativa do Brasil. Brasília, DF: Senado Federal: Centro Gráfico, 1988. Artigo 225.

3 BRASIL. Lei $\mathrm{n}^{\mathbf{0}}$ 9.605, de 12 de fevereiro de 1988. Dispõe sobre as sanções penais e administrativas derivadas de condutas e atividades lesivas ao meio ambiente, e dá outras providências. Diário Oficial da República Federativa do Brasil. Brasília, 1988.
}

Revista de Biodireito e Direitos dos Animais | e-ISSN: 2525-9695 | Brasília | v. 2 | n. 1 | p. 1 - 19 | Jan/Jun. 2016. 
Em seguida, fará uma análise das bases da Ecologia Profunda, que em sua dimensão holística - e tanto quanto espiritual - empreende uma forte crítica ao princípio do desenvolvimento sustentável, que para os seus teóricos seria incapaz de oferecer respostas efetivas aos problemas decorrentes da grave crise ambiental em que o Planeta Terra se encontra.

Por fim, analisará os fundamentos teóricos da ecologia animalista, que reivindica uma ética que inclua os animais no círculo da moralidade, mas também na esfera jurídica, na condição de titulares de Direito, inclusive com abolição imediata do atual sistema de exploração institucionalizada.

Desse modo, o artigo fará uma análise panorâmica de algumas correntes dessas três vertentes ecofilosóficas, embora reconheçamos que outras delas, como o ecofeminismo e o gaianismo, tenham ficado de fora da análise, inobstante sua importância acadêmica.

\section{DO ANTROPOCENTRISMO PURO AO ANTROPOCENTRISMO ALARGADO}

Foi a partir dos sofistas gregos, mais precisamente a partir da famosa máxima de Protágoras de que "o Homem é medida de todas as coisas", que o mundo Ocidental começa a se afastar da perspectiva cosmocêntrica sustentada pelos ditos filósofos da natureza. 4

O antropocentrismo medieval, porém, não concedia ao homem mais privilégios sobre a natureza do que aqueles necessários para a obtenção do seu próprio sustento. Nesse paradigma o homem estava obrigado a conservar e melhor os recursos naturais. 5

No século XVII, o racionalismo moderno vai afastar esta concepção medieval moderada, fazendo renascer o antropocentrismo radical dos sofistas gregos, cabendo a Descartes, a partir da distinção entre res cogitans e res extensa legitimar o controle absoluto do homem, único animal racional, sobre a Natureza. ${ }^{6}$

\footnotetext{
${ }^{4}$ LEVAI, L. F. Direito dos animais. $2^{\text {a }}$ ed. Campos do Jordão: Mantiqueira, 2004,p.

${ }^{5}$ QUIRÓS, José Justo Megías. Dominacion sobre la naturaliza: de la escolástica al relativismo kantiano. Persona y Derecho. n. 70 (EneroJunio). 2014.1, ps. 158.

${ }^{6}$ QUIRÓS, José Justo Megías. Dominacion sobre la naturaliza: de la escolástica al relativismo kantiano. Persona y Derecho. n. 70 (EneroJunio). 2014.1, ps. 158. Para COIMBRA, José de Ávila Aguiar. MILARÉ, Edis; Antropocentrismo x ecocentrismo na ciência jurídica. Revista de Direito Ambiental, São Paulo: Revista dos Tribunais, ano 9, n. 36, out./dez. 2004, p.4: "Antropocentrismo é uma concepção genérica que, em síntese, faz o Homem o centro do Universo, ou seja, a referência máxima e absoluta de valores (verdade, bem, destino último, norma última e definitiva etc., de modo que ao redor desse "centro" gravitem todos os demais seres por força de um determinismo fatal."
} 
Descartes, por exemplo, com a expressão "Penso, logo existo" , já afirmava quea razão, porquanto atributo exclusivo do homem, excluiria por si só os animais de nossa esfera de consideração moral. ${ }^{7}$ Também Hegel, em sua Introdução à história da filosofia, afirma que:

Segundo uma antiga opinião, a faculdade de pensar é o que separa os homens dos brutos. Aceitamo-la como verdadeira. O que o homem possui de mais nobre do que o animal, possui-o graças ao pensamento: tudo quanto é humano, de qualquer forma que se manifeste, é-o na medida em que o pensamento age ou agiu. ${ }^{8}$

$\mathrm{Na}$ esteira desse pensamento, Celso Fiorillo afirma que o Direito ambiental incorpora necessariamente uma visão antropocêntrica de modo que, uma vez que o homem é o único animal racional, cabe unicamente a ele o direito à preservação das espécies, inclusive a própria, através das normas jurídicas. ${ }^{9}$

Para a tradição ocidental dominante, os animais e a natureza em geral estão a serviço do homem vez que eles são desprovidos de valor intrínseco, ${ }^{10}$ possuindo apenas valor instrumental para a consecução dos interesses humanos. Mesmo quando o homem protege os animais e a natureza, eles apenas estão salvaguardando os próprios interesses para gozo imediato ou futuro.

Relevante consignar o posicionamento de Nancy Mangabeira Unger, ao criticar o modelo de relacionamento do homem com a natureza na sociedade contemporânea, cuidando de memorar que ainda não foi superada a "razão instrumental", que explica como sendo a "postura que coloca o ser humano como um instrumento, como um meio para produzir determinado fim, pondo também a Natureza nesta mesma categoria." 11

Para Kant, filósofo que ainda hoje exerce uma enorme influência no mundo jurídico, é impossível uma relação jurídica entre os homens e os animais, uma vez que o Direito é bilateral - para cada direito corresponde um dever - e como os animais não possuem nem direitos nem deveres, isto não é possível. ${ }^{12}$

\footnotetext{
${ }^{7}$ DESCARTES, René. Discurso do método. Tradução de: Maria E. Galvão. São Paulo: Martins Fontes, 1996, p. 38.

${ }^{8}$ HEGEL, Georg Wilhelm Friedrich. Introdução à história da filosofia. São Paulo: Saraiva, 2011, p.11

9 FIORILLO, Celso A. P. Curso de Direito Ambiental Brasileiro. Rio de Janeiro:Saraiva.2013, p.69

${ }^{10}$ SINGER, Peter. Ética prática. Trad. Jefferson Luiz Camargo. São Paulo: Martins Fontes, 2006. Nas lições do próprio Singer, p. 290: “uma coisa tem valor intrínseco se for boa ou desejável em si; o contraste se dá com o valor instrumental, que é um valor em forma de meio para a obtenção de algum outro fim ou objetivo."

11 UNGER, Nancy M. O encantamento do humano. São Paulo: Loyola, 1991. P. 55

${ }^{12}$ KANT, Immanuel. Introdução ao estudo do direito: doutrina do direito.Trad. Edson Bini. São Paulo: Edipro, 2007.
}

Revista de Biodireito e Direitos dos Animais | e-ISSN: 2525-9695 | Brasília | v. 2 | n. 1 | p. 1 - 19 | Jan/Jun. 2016. 
Não obstante, a tomada de consciência acerca do esgotamento dos recursos naturais e da possibilidade de extinção das diversas espécies - que vem afetando negativamente não somente a estrutura econômica social, mas também as oportunidades recreativas - tem permitido o abrandamento da visão antropocêntrica tradicional em relação à natureza e os animais. 13

De fato, a partir do discurso intergeracional - que visa assegurar às gerações vindouras o direito de usufruir dos recursos naturais - despontam argumentos em defesa do bem-estar e de um tratamento mais humanitário dos animais não humanos. ${ }^{14}$

Trata-se do antropocentrismo alargado, que reivindica a inclusão da natureza e dos animais em nosso círculo de moralidade, uma vez que nós muitas vezes temos a obrigação moral de respeitar a natureza, mesmo quando ela contrarie os nossos interesses, embora isso não signifique que eles possam ser titulares de direitos . 15

Apelidado por Jose Roque Junges SJ de antropocentrismo débil (em que pese não se perceba pejoratividade no discurso do teólogo), a perspectiva mais branda do antropocentrismo, em realidade, implica a admissão da existência de deveres humanos para com a natureza, ainda que indiretos e, por conseguinte, no estabelecimento de limites à intervenção na natureza 16 .

\footnotetext{
13 BENJAMIN, Antônio Herman. A Natureza no Direito Brasileiro: coisa, sujeito ou nada disso.Caderno Jurídico da Escola Superior

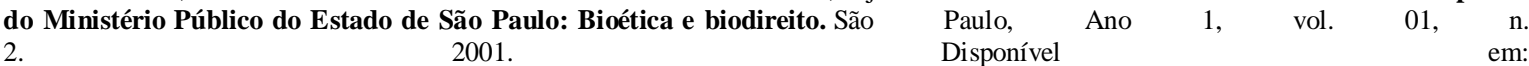
<http://www.mpsp.mp.br/portal/page/portal/Escola_Superior/Biblioteca/Cadernos_Tematicos/bioetica_e_biodireito.pdf $>$ Acesso em 01 jul 2015. P. 8

${ }^{14}$ Ibidem, p. 86.

15 JUNGES SJ, Jose Roque. Ética ecológica: antropocentrismo ou biocentrismo? Perspectiva Teológica. Vol. $\quad 33, \quad \mathrm{n}$. 89, 2001. Disponível em: <http://faje.edu.br/periodicos2/index.php/perspectiva/article/view/801>.Acesso em: 02 jul. 2015. P. 36

16 JUNGES SJ, Jose Roque. Ética ecológica: antropocentrismo ou biocentrismo? Perspectiva Teológica. Vol. $\quad 33, \quad n$. 89, 2001. Disponível em: <http://faje.edu.br/periodicos2/index.php/perspectiva/article/view/801〉.Acesso em: 02 jul. 2015. P. 36
} 


\section{O STATUS MORAL E JURÍDICO DOS ANIMAIS NAS CORRENTES} ANIMALISTAS

A ecologia animalista almeja a consecução de mudanças éticas significativas no tratamento que dispensamos aos animais, através de alterações comportamentais e jurídicas que sejam capazes de afetar positivamente as condições de vida dessas criaturas. ${ }^{17}$

O discurso em favor da salvaguarda dos interesses dos animais, todavia, não se revela homogêneo, ora incluindo os animais apenas no círculo da moralidade, ora considerando os animais sujeitos de direito.

O animalismo abolicionista sustenta que a exploração institucionalizada dos animais é análoga à escravidão, reivindicando a total abolição desta condição a partir do reconhecimento de que os animais são sujeitos de direito, ${ }^{18}$ e não propriedade. ${ }^{19}$

Para Carlos Naconecy, “diferentemente de quaisquer coisas que possuímos, os animais têm o direito básico de não serem item de propriedade de seus donos. Podemos chamar esse direito básico de "proto-direito", isto é, o direito de ter outros direitos. 20

Assim, assentada a premissa de que a atribuição de status jurídico de coisa trata- se de equívoco, os animalistas abolicionistas sustentam a necessidade de serem imputados aos animais direitos básicos semelhantes àqueles assegurados aos homens: direito à vida, direito à liberdade, direito à integridade física e psíquica, o que implicaria, por conseguinte, na vedação ao aprisionamento, abate e tortura ${ }^{21}$.

\footnotetext{
${ }^{17}$ REGAN, Tom. A causa dos direitos dos animais.RevistaBrasileira de Direito Animal n.12vol 8, Jan- Abr. 2013 p. 20.

18 GORDILHO, Heron José de Santana. Direito Ambiental Pós-Moderno. Curitiba: Juruá, 2011. Para Gordilho,p. 123: “Ainda hoje, no entanto, milhões de animais sencientes, nascidos livres, são roubados, capturados, mutilados, vendidos como mercadoria, espoliados na realização de trabalhos forçados, ou simplesmente mortos e devorados, sem qualquer direito a defesa, e poucos de nós se compadece com o sofrimento desses seres, muitos deles tão próximos de nós na cadeia evolutiva".

19 FRANCIONE, Gary. Rain without Thunder. The ideology of the Animal Rights Movement.Philadelphia:Temple University Press, 1996. Segundo Francione, p. 02: "And because rights theory rejects the treatment of animals as property, rights theory rejects completely the institutionalized exploitation of animals, which is made possible only because animals have property status." Tradução livre da autora: "E porque a teoria dos direitos rejeita o tratamento dos animais como propriedade, a teoria dos direitos rejeita completamente a exploração institucionalizada dos animais, o que só se torna possível porque os animais têm o estatuto de propriedade."

${ }^{20}$ NACONECY, Carlos. Bem-estar animal ou libertação animal? Uma análise crítica da argumentação antibem-estarista de Gary Francione. Revista Brasileira de Direito Animal. Vol. 4 4, n. $2009 . \quad$ Disponível: <http://www.portalseer.ufba.br/index.php/RBDA/article/viewFile/10633/7678> Acesso em: 01 jul. 2015. P. 239

${ }^{21}$ GORDILHO, Heron. Abolicionismo animal. Salvador: Evolução. 2009, p. 142
} 
Para sustentar a necessidade de serem atribuídos direitos morais ${ }^{22}$ aos animais, Tom Regan amplia o conceito kantiano de "pessoa", 23 para demonstrar que muitos animais, especialmente os mamíferos adultos são "sujeitos de uma vida", isto é, são criaturas dotadas de um estado de consciência e de atributos como interesses, crenças, desejos, percepções, sentimentos, emoções, memórias, frustrações, capacidades psicológicas e emocionais bem desenvolvidas. $^{24}$

O animalismo benestarista, por seu turno, discorda da abolição imediata da exploração institucionalizada dos animais e reivindica apenas o controle e regulação dessa exploração através da adoção de ações voltadas à mitigação do sofrimento desnecessário dos animais.

Para o animalismo benestarista de matiz utilitarista, como o de Peter Singer, não existe nada de errado em utilizar animais em pesquisa científica ou até mesmo em vendê-los como alimentação, uma vez que o mais importante é a quantidade de sofrimento imposto ao animal. ${ }^{25}$ Para orientar a experimentação animal, por exemplo, as ideais benestaristas se fundamentam em um Princípio Humanitário denominado de doutrina dos 3 Rs: substituição (replacement), redução (reduction) e refinamento (refinement).

A redução relaciona-se à orientação de se utilizar o menor número possível de animais no experimento, não ultrapassando a quantidade necessária à obtenção de resultados estatísticos relevantes; ao passo que a substituição reivindica uma progressiva substituição do uso de animais por recurso alternativos que possam se mostrar viáveis à obtenção do resultado almejado, à exemplo de culturas de tecido humano. Quando a utilização de animais for imprescindível, orienta-se a substituição de mamíferos por outros

\footnotetext{
${ }^{22}$ REGAN, Tom. Jaulas vazias. Trad. Regina Rheda. Porto Alegre: Lugano, 2006. p. 47: "Possuir direitos morais é ter um tipo de proteção que poderíamos imaginar como um sinal invisível dizendo: 'Entrada Proibida'. O que esse sinal pró́be? Duas coisas. Primeira: ou outros não são moralmente livres para nos causar mal; [...]"

23 KANT, Immanuel. Introdução ao estudo do direito: doutrina do direito.Trad. Edson Bini. São Paulo: Edipro, 2007, p. 36: “ Uma pessoa é um sujeito cujas ações lhe podem ser imputadas. A personalidade moral não é, portanto, mais do que a liberdade de um ser racional submetido a leis morais

(enquanto a personalidade psicológica é meramente a faculdade de estar consciente da própria identidade em distintas condições da própria existência. Disto resulta que uma pessoa não está sujeita a outras leis senão àquelas que atribui a si mesma (ou isoladamente ou, ao menos, juntamente com outros)."

${ }^{24}$ GORDILHO, Heron .Abolicionismo Animal. Salvador: Evolução, 2008, p. 72.

${ }^{25}$ SILVA, Tagore. Animais em juízo. Salvador: Evolução, 2012, p. 20.
}

Revista de Biodireito e Direitos dos Animais | e-ISSN: 2525-9695 | Brasília | v. 2 | n. 1 | p. 1 - 19 | Jan/Jun. 2016. 
animais com sistema nervoso menos desenvolvido; por fim, o refinamento exige que o manejo dos animais utilizados no experimento seja realizado por indivíduo tecnicamente habilitado, evitando-se que eventuais imperícias possam vir

a causar sofrimento ainda maior ao animal. 26

Ademais, justifica-se a experimentação animal nas hipóteses em que os ônus (sejam aos homens, sejam aos animais) sejam inferiores ao patamar de benefícios auferidos, o que, nas palavras de Rivera “... exige que se obtenha um ganho maior de conhecimento com um custo menor no número de animais utilizados e com o menor sofrimento por parte destes". 27

De fato, ao adotar como ponto de partida as idéias utilitaristas de Jeremy Bentham, Peter Singer afirma que toda ação ou decisão deve ser considerada justa somente quando resultar num elevado benefício social, mesmo que esse benefício tenha um custo significativo para determinada minoria. 28

Para Singer, diante de uma decisão a ser tomada, deve ser realizado o cômputo do montante de prazer a ser gerado, bem como do total de sofrimento a ser impingido, ambos individualmente considerados para fins de quantificação, de forma que a ação somente será considerada boa se o resultado for favorável ao prazer. Em suas palavras, pode-se considerar uma ação correta se "comparada a uma ação alternativa, ela produza um aumento maior ou igual da felicidade de todos os que são por ela atingidos, e errada desde que não consiga fazêlo. As conseqüências de uma ação variam de acordo com as circunstâncias na qual ela é praticada." 29

Em termos mais simples, uma ação será eticamente positiva se o número de indivíduos que experimentem prazer com o resultado superar o número de indivíduos que experimentem dor (deve-se estar a falar, todavia, em sofrimento/prazer de mesma intensidade). Há de ser analisada, sempre, as conseqüências do ato a ser praticado.

\footnotetext{
26 RIVERA, EkaterinaAkimovna B. Ética na experimentação animal. Revista de Patologia Tropical. Vol. 30, n. 01, 2001. Disponível em: <http://www.revistas.ufg.br/index.php/iptsp/article/view/15790> Acesso em 04 jul. 2015. p. 11

27 Ibidem, p. 12.

${ }^{28}$ GORDILHO, Heron. Abolicionismo animal. Salvador: Evolução. 2009, p. 66.

${ }^{29}$ SINGER, Peter. Ética prática. Trad. Jefferson Luiz Camargo. São Paulo: Martins Fontes, 2006, p. 111
}

Revista de Biodireito e Direitos dos Animais | e-ISSN: 2525-9695 | Brasília | v. 2 | n. 1 | p. 1 - 19 | Jan/Jun. 2016. 
Sucede que, na construção do seu discurso, Singer passa a levar em consideração também os interesses dos animais capazes de experimentar dor e prazer, em patamar equivalente aos interesses dos seres humanos, porquanto adote como critério a quantificação do sofrimento e, por conseguinte, a existência de interesses. 30

Ocorre que Singer, apesar de valorar os interesses dos animais, não nega ser a vida humana mais importante que a vida de um animal. Desta feita, entende que os animais podem vir a ser mortos em benefício do ser humano, desde que não lhes seja violado o interesse de não sentir dor. 31

Explica-se: para Singer, interesse em não sentir dor e interesse no prolongamento da vida são coisas distintas, residindo o critério diferenciador na capacidade cognitiva. Àqueles indivíduos capazes de elaborar preferências em relação ao futuro 32 deve ser atribuído o interesse à vida. Entrementes, àqueles não autoconscientes, apenas subsiste o interesse em não sofrer/obter prazer.

Desta feita, à luz desse tipo de lógica, o sacrifício de um indivíduo não consciente da sua própria mortalidade seria menos prejudicial que a morte de um indivíduo consciente de si, 33 o que justificaria a exploração dos animais não autoconscientes em certas circunstâncias, desde que preservado o seu interesse em não sentir dor.

\footnotetext{
${ }^{30}$ SINGER, Peter. Ética prática. Trad. Jefferson Luiz Camargo. São Paulo: Martins Fontes, 2006,p. 68: “Quando um ser não for capaz de sofrer, nem de sentir alegria ou felicidade, não haverá nada a ser levado em consideração. É por esse motivo que o limite da sensibilidade [...] é o único limite defensável da preocupação com os interesses alheios. Demarcar esse limite através de uma característica, como a inteligência ou a racionalidade, equivaleria a demarcá-lo de modo arbitrário."

31 Ibidem, p. 71.

32 ABOGLIO, Ana María. Utilitarismo e bem-estarismo: Esclarecimentos para aprofundar a compreensão das diferenças substanciais com relação à Teoria dos Direitos Animais. Trad. Regina Rheda. Disponível em: <http://www.anima.org.ar/libertacao/abordagens/utilitarismo-e-bem- estarismo.pdf> Acesso em: 02 jul. 2015. p.3.

${ }^{33}$ SINGER, Peter. Ética prática. Trad. Jefferson Luiz Camargo. São Paulo: Martins Fontes, 2006, p.100 “Haverá um valor especial na vida de um ser racional e autoconsciente, por oposição a um ser que seja meramente senciente? Uma linha de argumentação para responder a essa pergunta de modo afirmativo pode ser desenvolvida da maneira como apresentaremos a seguir. Um ser autoconsciente tem consciência de si enquanto entidade distinta, com um passado e um futuro. (Este, lembremo-nos, era o critério mediante o qual Locke definia uma pessoa.) Um ser dotado de consciência de si será capaz de ter desejos relativos a seu próprio futuro. [...] Tirar a vida dessas pessoas sem o seu consentimento significa frustrar os seus desejos para o futuro.[...] Já os seres que não conseguem ver-se como entidades dotadas de um futuro não pode ter quaisquer preferências a respeito de sua existência futura. Isto não equivale a negar que tais seres pudessem lutar contra uma situação na qual as suas vidas estivessem correndo perigo, como um peixe luta para livrar-se do anzol em sua boca; mas não indica mais que a preferência pela cessação de um estado de coisas percebido como doloroso ou amedrontador. O comportamento de um peixe fisgado sugere uma razão para não se matar um peixe por esse método, mas, em si, não sugere uma razão de preferência utilitária contra o fato de se matar um peixe por um método que provoque morte instantânea, sem antes provocar dor ou sofrimento."
}

Revista de Biodireito e Direitos dos Animais | e-ISSN: 2525-9695 | Brasília | v. 2 | n. 1 | p. 1 - 19 | Jan/Jun. 2016. 


\section{ECOLOGIA PROFUNDA: A NATUREZA DENTRO DA LEI}

A Ecologia Profunda foi proposta em 1973 pelo filósofo norueguês Arne Naess, no artigo "The shallow and the Deep, Long-Range Ecology Movements", onde demonstra que existem dois tipos de ecologia que competem por atenção: uma rasa e dominante; outra profunda, todavia ainda pouco influente. 34

A primeira, associada aos conceitos de desenvolvimento sustentável e solidariedade intergeracional, concentra seus esforços na luta contra a poluição e a degradação dos recursos ambientais, visando salvaguardar o direito das futuras gerações de usufruir os bens naturais. A segunda se fundamenta na idéia central de que a natureza possui valor em si mesma, independentemente da utilidade econômica que tem para o

ser humano. 35

Motivado pelo incremento da preocupação com as questões ambientais no panorama mundial, especialmente a partir da Primeira Conferência Mundial Sobre o Homem e o Meio Ambiente realizada em Estocolmo, na Suécia, Naees tenda fazer uma abordagem mais profunda e espiritual da Natureza a partir dos exemplos de Aldo Leopold e Rachel Carson. 36

Para Naess, a Ecologia profunda possui duas regras fundamentais: a) autorealização, que vai além da noção ocidental de um ego isolado lutando por gratificações hedonísticas e do sentido raso de salvação individual nesta ou em outra vida. O desenvolvimento espiritual começa quando deixamos de nos ver como limitados e isolados egos competidores e começamos a nos identificar como membros de nossa família, amigos e mesmo de nossa espécie; b) igualdade biocêntrica, que assegura que todas as coisas da biosfera possuem um direito igual de viver, desabrochar e buscar sua própria auto-realização, uma vez

\footnotetext{
${ }^{34}$ NAESS, Arne. The shallow and the deep, long-range ecology movement.InterdisciplinaryJournalofPhilosophy, A summary', Inquiry, 16: 1, 95 - 100. Disponível em: <http://www.tandfonline.com/doi/abs/10.1080/00201747308601682> Acesso em: 16 mar. 2016. Passim.

35 NAESS, Arne. The shallow and the deep, long-range ecology movement.InterdisciplinaryJournalofPhilosophy, A summary', Inquiry, 16: 1, 95 - 100. Disponível em: <http://www.tandfonline.com/doi/abs/10.1080/00201747308601682> Acesso em: 16 mar. 2016. Passim.

36 SESSIONS, George \& DEVALL, Bill. Deep Ecology. Salt Lake Cituy: Peregrine Smith Books. 1985, p.65
}

Revista de Biodireito e Direitos dos Animais | e-ISSN: 2525-9695 | Brasília | v. 2 | n. 1 | p. 1 - 19 | Jan/Jun. 2016. 
que todo organismo ou ente da ecosfera, como parte integrante de um todo, tem igual valor intrínseco. 37

É importante destacar que a Ecologia Profunda sofreu forte influência da "Ética da Terra" de Aldo Leopold,que, a partir do axioma da integridade, entende que o uso ético dos elementos naturais só ocorre quando esse uso consegue preservar a integridade, a estabilidade e a beleza da comunidade biótica, aí incluído o solo, as águas, a fauna, a flora e também as pessoas". 38

Em 1949, Leopold publicou A Sand County Almanac, e no famoso capítulo denominado "Pensando como uma montanha" analisa como a morte de um lobo predador pode provocar sérias implicações para o ecossistema. 39

Para ele, assim como as escravas mortas por Odisseu, o planeta não faz parte da comunidade moral porque é considerado uma simples commodity, de modo que todas as formas de vida, e os próprios ecossistemas, devem ser considerados entes morais e titulares de direitos fundamentais ou direitos bióticos (bioticrights), como "o direito a uma existência continuada", uma vez que o homem e a natureza são iguais ecologicamente (igualitarismo ecológico). 40

Seja como for, para compreender a dicotomia Ecologia Rasa e Ecologia Profunda é preciso tomar por empréstimo as críticas lançadas por Van Rensselaer Potter ao célebre princípio do desenvolvimento sustentável, que em sua obra denominada Global Bioethics: Converting Sustainable Developmentto Global Survival, ele alerta para a necessidade de substituição da ideia de desenvolvimento sustentável (e suas implicações) pela noção de sobrevivência global aceitável. ${ }^{41}$

\footnotetext{
${ }^{37}$ SESSIONS, George \& DEVALL, Bill. Deep Ecology. Salt Lake Cituy: Peregrine Smith Books. 1985, p.66.

${ }^{38}$ LEOPOLD, A Sand County Almanac, op.cit, p. 262

39 Ibid

${ }^{40}$ LEOPOLD, A Sand County Almanac,op.cit, p. 209.

${ }^{41}$ POTTER, Van Rensselaer. Global Bioethics: building on the Leopold legacy. East Lansing: Michigan State University Press, 1988. P. 188.
}

Revista de Biodireito e Direitos dos Animais | e-ISSN: 2525-9695 | Brasília | v. 2 | n. 1 | p. 1 - 19 | Jan/Jun. 2016. 
Para ele, a expressão desenvolvimento sustentável - porquanto carregue consigo duas ideias nucleares, desenvolvimento e sustentabilidade (a primeira, atrelada à ideia de crescimento, expansão do número de empreendimentos bem sucedidos, e a segunda, conexa à necessidade assegurar a existência dos recursos naturais por mais algumas décadas) - é um conceito antropocêntrico voltado à salvaguarda dos interesses econômicos da presente e futuras gerações. 42

Trata-se, portanto, de uma acepção preponderantemente quantitativa, onde o que se almeja não é a tutela da natureza em si, mas a garantiade que gerações futuras possam também fruir, usar e dispor dos seus recursos.

Por outro lado, à ideia de sobrevivência global aceitável assume um comprometimento ético, uma tomada de consciência acerca da posição do homem no contexto da biosfera e da sua responsabilidade pela sobrevivência de todos os seres vivos, inclusive a sua própria. $\mathrm{Na}$ ecologia profunda, a tutela ambientalé analisada sob um prisma qualitativo. 43

Outro filósofo de destaque é Albert Schweitzer, que utiliza um ponto de partida "místico " para estabelecer as bases de sua ética da "reverência pela vida", que exige que cada ser vivo tenha respeitado o seu direito de viver, pois a eliminação de uma vida somente se justifica em situação de absoluta necessidade. 44

Para John Muir, ${ }^{45}$ naturalista escocês erradicado nos EUA, onde fundou a ONG Sierra Club, uma das primeiras associações do mundo a ter como objetivo a proteção da natureza, o homem é parte da própria natureza, e como tal não pode ser dotado de

\footnotetext{
${ }^{42}$ POTTER, Van Rensselaer. Global Bioethics: building on the Leopold legacy. East Lansing: Michigan State University Press, 1988. P. 188. 43 Ibid.

44 CICOVACKI, Predrag. Albert Schweitzer's ethical vision: a sourcebook.Oxford University Press. 2009. disponível em: https://books.google.com.br/books?id=MPIJCAAAQBAJ\&pg=PT31\&lpg=PT31\&dq=SCHWEITZER,+ Albert.+Out+of+My+Life+and+Thought:+An+Autobiography.+New+York:+John+Hopkins+University+Press, $+1998 . \&$ source=bl\&ots=nkVVy G7Z1 m\&sig=H8BoOWVHkPnZgNYMfbu8FtOpP6E\&hl=pt-

R\&sa=X\&ved=0ahUKEwjR6uPQuMfLAhVCaRQKHTZ7BNEQ6AEIHzAA\#v=onepage\&q=SCHWEI TZER\%2C\%20Albert.\%20Out\%20of\%20My\%20Life\%20and\%20Thought\%3A\%20An\%20Autobiograp hy.\%20New\%20York\%3A\%20John\%20Hopkins\%20University\%20Press\%2C\%201998.\&f=false, acessadoem 16.03.2016.

45 MUIR, John. A Thousand-Mile Walk of the Gulf.Boston and New York: Hopughton Mifflin Company.1916. Disponívelem: http://www.yosemite.ca.us/john_muir_writings/a_thousand_mile_walk_to_the_gulf/a_thousand_mile_wa lk_to_the_gulf.pdf . Acessado em 15.03.2016.
}

Revista de Biodireito e Direitos dos Animais | e-ISSN: 2525-9695 | Brasília | v. 2 | n. 1 | p. 1 - 19 | Jan/Jun. 2016. 
direitos maiores que os animais, idéias que, mais tarde, foram chamadas de biocentrismo. Muir é um dos primeiros autores a falar em "direitos da natureza”, por considerar que vez que os animais, as plantas e até mesmo as rochas, possuem, além da beleza, um valor intrínseco. 46

Em 1981, Paul Taylor escreve The ethics of rerspect for nature, para afirmar que todas as coisas vivas são "centros teleológicos de vida”, com as quais nós temos deveres morais de não-maleficência, não-interferência, fidelidade e justiça restitutiva. ${ }^{47}$

É que para a ecologia profunda, o ecossistema é uma complexa teia de elementos interligados onde a função biológica de cada um depende da função biológica dos demais, e a própria sobrevivência do ser humano depende dessa harmonia ecossistêmica. 48

Importante destacar que essa ética ecológica possui uma perspectiva espiritual ou religiosa, e para Fritjof Capra:

[...] quando a concepção de espírito humano é entendida como o modo de consciência da qual o indivíduo tem uma sensação de pertinência, de conexidade com o cosmos como um todo, torna-se claro que a percepção ecológica é espiritual na sua essência mais profunda. 49

Nancy Mangabeira Unger, ao expor as bases do movimento ecológico, também destaca a reaproximação das dimensões social e espiritual ao afirmar que o que o pensamento ecológico tem de mais rico é essa possibilidade de juntar a dimensão da polis, ou seja, aquele espaço que é próprio à comunidade dos homens, com a dimensão

dos cosmos, que é nossa relação com o Universo. 50

\footnotetext{
46 WOLFE, LinnieMarsh (ed.). John ofthe Mountains: theUnpublishedJournalsof John Muir.Wisconsin:Universityof Wisconsin Press, 1979, p. 138.

${ }^{47}$ TYLOR, Paul. The ethics of Rrspect for nature.Environmental Ethics, Vol. 3, No. 3 (Fall 1981),p.86. Disponivel em http://www.manifestoantispecista.org/wp-content/uploads/2012/01/il-biocentrismo-individualistico-di-taylor-definitivo.pdf, acessado em 16.03.2016.

${ }^{48}$ CAPRA, Fritjof.A teia da vida: uma nova compreensão científica dos sistemas vivos.Trad. Newton Roberval Eichemberg. São Paulo: Cultrix, 2006. P. 25

49 CAPRA, Fritjof.A teia da vida: uma nova compreensão científica dos sistemas vivos.Trad. Newton Roberval Eichemberg. São Paulo: Cultrix, 2006. P. 25: "A ecologia profunda reconhece o valor intrínseco de todos os seres vivos e concebe os seres humanos apenas como um fio particular na teia da vida."

${ }^{50}$ UNGER, Nancy Mangabeira. O encantamento do humano.São Paulo: Loyola, 1991,p. 60.
}

Revista de Biodireito e Direitos dos Animais | e-ISSN: 2525-9695 | Brasília | v. 2 | n. 1 | p. 1 - 19 | Jan/Jun. 2016. 
Trata-se, portanto, de uma visão holística e não hierarquizada do meio ambiente, onde todos os seres vivos, porquanto detentores indistintamente de valor intrínseco, merecem igual respeito. 51

Como visto, um dos mandamentos basilares do ecologismo profundo, 52 é o princípio do igualitarismo biosférico, segundo o qual todas as formas de vida possuem, $a$ princípio, equivalente direito de viver e florescer, devendo ser respeitadas, até mesmo veneradas. 53

Não obstante, como toda práxis realista exige alguma exploração ou supressão, Naess cuida de elencar as premissas do ecologismo profundo, a saber: a) O bem-estar e florescimento da vida humana e não humana na Terra têm valor inerentes. Estes valores independem da utilidade do mundo não humano para fins humanos; b) A riqueza e diversidade das formas de vida contribuem para a realização desses valores e são também valores em si mesmos; c) Os seres humanos não têm o direito de reduzir esta riqueza e diversidade, exceto para satisfazer as necessidades vitais; d) O florescimento da vida humana e desenvolvimento cultural são compatíveis com uma diminuição substancial da população humana. O florescimento da vida não humana requer uma tal diminuição; e) A presente interferência humana com o mundo não-humano é excessiva, ea situação está piorando rapidamente; f) As políticas devem, portanto, ser alteradas. Estas políticas afetam basicamente estruturas econômicas, tecnológicas e ideológicas; g) A escolha ideológica é, principalmente, a de valorizar a qualidade de em vez de aderir a um nível cada vez mais elevado de vida; h) Aqueles que anuírem com os pontos precedentes têm a obrigação de diretamente ou indiretamente tentar implementar as mudanças necessárias. 54

\footnotetext{
${ }^{51}$ Segundo SESSIONS, George \& DEVALL, Bill.Deep Ecology. Salt Lake Cituy: Peregrine Smith Books. 1985, p.65: "Por milhares de anos , a cultura Ocidental tem se tornado cada vez mais obcecada pela ideia de domínio : domínio dos humanossobre a Natureza, do masculine sobre o feminine, dos ricos e poderosos sobre os mais pobres, assimcomopelodomínio da culturaOcidentalsobre as culturasnãopOcidentais. A conciênciaecológicaprofundanos permit ever alémdessasperigosas e equivocadasilusões. (traduçãonossa)

52 NAESS, Arne. The shallow and the deep, long-range ecology movement.InterdisciplinaryJournalofPhilosophy, A summary', Inquiry, $16: \quad 1, \quad 95 \quad-\quad 100$. Disponível em: <http://www.tandfonline.com/doi/abs/10.1080/00201747308601682> Acesso em: 13 mar. 2015, p. 95.

${ }^{53}$ Ibid.

54 NAESS, Arne. The shallow and the deep, long-range ecology movement.InterdisciplinaryJournalofPhilosophy, A summary', $\quad$ Inquiry, $\quad 16: \quad 1, \quad 95 \quad-\quad 100 . \quad$ Disponível em: <http://www.tandfonline.com/doi/abs/10.1080/00201747308601682> Acesso em: 13 mar. 2016, p. 99.
} 
Para Junges, a ecologia profunda “ não se trata de uma ética no sentido da elaboração de normas e imperativos, mas de uma total conversão e excelência moral. Assim surge um ser humano 'ecóico' em vez de 'egóico' que se compreende essencialmente como um ser em relação."55

Para George Sessions e Bill Deval, os animalistas, que tentam unilateralmente resolver esse problema através do vegetarianismo, terão que advogar que todo o reino vegetal, inclusive as florestas tropicais, não possuem nenhum direito à existência própria, e está é uma posição o que viola a regra fundamental da igualdade biocentrica. 56

Em suma, ainda que a Ecologia Profunda considere os animais e os elementos da natureza titulares de direitos morais, a sua perspectiva holísitica está maisprocupada com o todo do que com as partes - os indivíduos - , de modo que o homem tem o direito utilizar os animais e os demais elementos da natureza para satisfazer necessidades básicas, desde que isso não comprometa o equilíbrio do ecossistema.

\section{CONCLUSÃO}

Com o presente escrito, pretendeu-se despertar a atenção do leitor para pluralidade de sistemas éticos sobre as relações homem/natureza e homem/animais, uma vez que cada uma delas defende valores e princípios distintos, ora admitindo a inclusão dos elementos da natureza no círculo da moralidade, ora considerando-os como sujeito de direito.

O intento do presente trabalho desvelou-se justamente neste sentido de fornecer subsídios mínimos e informações basilares acerca dos elementos axiológicos constantes dos diversos discursos éticos emergentes, convidando o leitor ao aprofundamento.

As divergências acadêmicas entre antropocentristas, puros e alargados, animalistas, benestaristas e abolicionistas e ecologistas profundos, holistas e individualistas, mostram muito bem que a Direito Ambiental e o Direito Animal podem se constituir em preciosos campos de pesquisa a serem explorados.

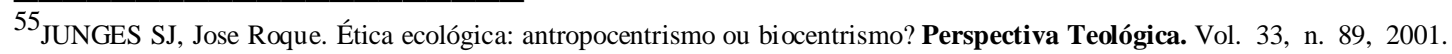
Disponível em: <http://faje.edu.br/periodicos2/index.php/perspectiva/article/view/801> Acesso em: 02 jul. 2015, p. 39. Acesso em 19.02.2016.

${ }^{56}$ SESSIONS, George \& DEVALL, Bill. Deep Ecology. Salt Lake Cituy: Peregrine Smith Books. 1985, p. 65-66.
}

Revista de Biodireito e Direitos dos Animais | e-ISSN: 2525-9695 | Brasília | v. 2 | n. 1 | p. 1 - 19 | Jan/Jun. 2016. 
Desde os anos 90, o Direito Ambiental tem se constituído em uma importante disciplina nas faculdades de direito brasileiras, e o estudo das principais correntes ecofilosóficas pode ser um importante instrumento no processo de interpretação das normas jurídicas ambientais.

Além disso, assistimos ao surgimento de uma nova disciplina jurídica no Brasil: o Direito Animal, que já se constitui em disciplina em alguns cursos de graduação e de pós-graduação, a exemplo da Faculdade de Direito da Universidade Federal da Bahia, cujo Programa de PósGraduação já oferece inclusive uma linha de pesquisa sobre o tema.

Seja como for, o estudo das três ecofilosofias pode auxiliar sobremaneira os operadores do direito na resolução dos conflitos ambientais, permitindo a ele encontrar sofisticados fundamentos teóricos para as suas interpretações.

\title{
REFERÊNCIAS
}

\begin{abstract}
ABOGLIO, Ana María. Utilitarismo e bem-estarismo: Esclarecimentos para aprofundar a compreensão das diferenças substanciais com relação à Teoria dos Direitos Animais. Trad. Regina Rheda. Disponível em: <http://www.anima.org.ar/libertacao/abordagens/utilitarismo-e-bem-estarismo.pdf > Acesso em: 02 jul. 2015.
\end{abstract}

BENJAMIN, Antônio Herman. A Natureza no Direito Brasileiro: coisa, sujeito ou nada disso. Caderno Jurídico da Escola Superior do Ministério Público do Estado de São Paulo: Bioética e biodireito. São Paulo, Ano 1, vol. 01, n. 2. 2001. Disponível em: <http://www.mpsp.mp.br/portal/page/portal/Escola_Superior/Biblioteca/Cadernos_Tem aticos/bioetica_e_biodireito.pdf> Acesso em 01 jul 2015.

BRASIL. Constituição (1988). Constituição da República Federativa do Brasil. Brasília, DF: Senado Federal: Centro Gráfico, 1988. Artigo 225.

Lei $\mathrm{n}^{\circ}$ 9.605, de 12 de fevereiro de 1988. Dispõe sobre as sanções penais e administrativas derivadas de condutas e atividades lesivas ao meio ambiente, e dá outras providências. Diário Oficial da República Federativa do Brasil. Brasília, 1988. CAPRA, Fritjof.A teia da vida: uma nova compreensão científica dos sistemas vivos. Trad. Newton Roberval Eichemberg. São Paulo: Cultrix, 2006.

CICOVACKI, Predrag. Albert Schweitzer's ethical vision: a sourcebook. Oxford: Oxford University Press. 2009 
COIMBRA, José de Ávila Aguiar. MILARÉ, Edis; Antropocentrismo x ecocentrismo na ciência jurídica. Revista de direito ambiental, São Paulo: Revista dos Tribunais, ano 9, n. 36, p. 9-41 out./dez. 2004.

DESCARTES, René. Discurso do método. Trad. Maria E. Galvão. São Paulo: Martins Fontes, 1996.

FIORILlO, Celso. Curso de Direito Ambiental Brasileiro. Rio de Janeiro: Saraiva.2013.

FRANCIONE, Gary. Rain without Thunder. The ideology of the Animal Rights Movement. Philadelphia: TempleUniversity Press,1996.

GORDILHO, Heron José de Santana. Direito Ambiental Pós-Moderno. Curitiba: Juruá. 2011.

Abolicionismo animal. Salvador: Evolução. 2009

HEGEL, Georg. Introdução à história da filosofia.São Paulo: Saraiva, 2011.

JUNGES SJ, Jose Roque. Ética ecológica: antropocentrismo ou biocentrismo? Perspectiva Teológica. Vol. 33, n. 89, 2001. Disponível em: <http://faje.edu.br/periodicos2/index.php/perspectiva/article/view/801> Acesso em: 02 jul. 2015 .

KUHNEN. Tânia A. Um caso triangular na ética: limites da abordagem holista de J. Baird Callicott. Revista Brasileira de Direito Animal. Vol. 9, n. 17, 2014. Disponível::<http://www.portalseer.ufba.br/index.php/RBDA/article/viewFile/12984/92 81> Acesso em: 02 jul. 2015.

LEVAI, L. F. Direito dos animais.2 ${ }^{a}$ ed. Campos do Jordão: Mantiqueira, 2004. LEOPOLD, Aldo. A sand county almanac: and sketches here and there. US: Oxford University Press, 1949

NAESS, Arne. The shallow and the deep, long-range ecology movement. Interdisciplinary Journal of Philosophy, A summary', Inquiry, 16: 1, 95 - 100. Disponível em: 
<http://www.tandfonline.com/doi/abs/10.1080/00201747308601682> Acesso em: 13 mar. 2015.

POTTER, Lisa. Global Bioethics: converting Sustainable Development to Global Survival.Medicine and Global Survival, vol. 2, no. 3, 1995.Disponível em: <http://www.ippnw.org/pdf/mgs/2-3-potter.pdf.> Acessoem 07 mai. 2015.

POTTER, Van Rensselaer. Global Bioethics: building on the Leopold legacy. East Lansing: Michigan State University Press, 1988.

QUIRÓS, José Justo Megías. Dominacion sobre la naturaliza: de la escolástica al relativismo kantiano. Persona y Derecho. n. 70 (Enero-Junio). 2014.1, ps. 147-169.

REGAN, Tom. Jaulas vazias. Trad. Regina Rheda. Porto Alegre: Lugano, 2006.

A causa dos direitos dos animais. RevistaBrasileira de Direito Animal n.

RYDER, Richard. All beings that feel pain deserve human rights. The Guardian, 6 August 2005. Disponível em:

<http://www.guardian.co.uk/uk/2005/aug/06/animalwelfare> Acesso em: 05 jul. 2015.

RIVERA, Ekaterina Akimovna B. Ética na experimentação animal. Revista de Patologia Tropical. Vol. 30, n. 01, 2001. Disponível em: <http://www.revistas.ufg.br/index.php/iptsp/article/view/15790> Acesso em 04 jul. 2015.

SESSIONS, George \& DEVALL, Bill. Deep Ecology. Salt Lake Cituy: Peregrine Smith Books. 1985.

SILVA, Tagore Trajano de Almeida.Direito animal e os paradigmas de Thomas Kuhn. Reforma ou revolução científica na teoria do direito? Revista Brasileira de Direito Animal. Vol. 2, n. 03, 2007. Disponível em: <http://www.portalseer.ufba.br/index.php/RBDA/article/view/10365> Acesso em 03 jul. 2015.

.Animais em juízo. Salvador: Evolução, 2012.

SINGER, Peter. Ética prática. Trad. Jefferson Luiz Camargo. São Paulo: Martins Fontes, 2006.

Libertação animal. Porto Alegre:Lugano.2009.

TYLOR, Paul. The ethics of Respect for natur e.Environmental Ethics, Vol. 3, No. 3 (Fall 1981), p.86. Disponível em <http://www.manifestoantispecista.org/wp- 
content/uploads/2012/01/il-biocentrismo-individualistico-di-taylor-definitivo.pdf, > Acesso em 16 mar. 2016.

UNGER, Nancy Mangabeira. Crise ecológica: a deserção do espaço comum. Revista Educação e Realidade. Vol. 34, n. 03, 2009. Disponível em: <http://www.seer.ufrgs.br/educacaoerealidade/article/view/9542> Acesso em 04 jul 2015 .

O encantamento do humano.São Paulo: Loyola, 1991.

WOLFE, LinnieMarsh (ed.). John ofthe Mountains: theUnpublishedJournalsof John Muir.Wisconsin:Universityof Wisconsin Press, 1979. 